\title{
SOEP=-
}

SOEPpapers

SOEPpapers
on Multidisciplinary Panel Data Research

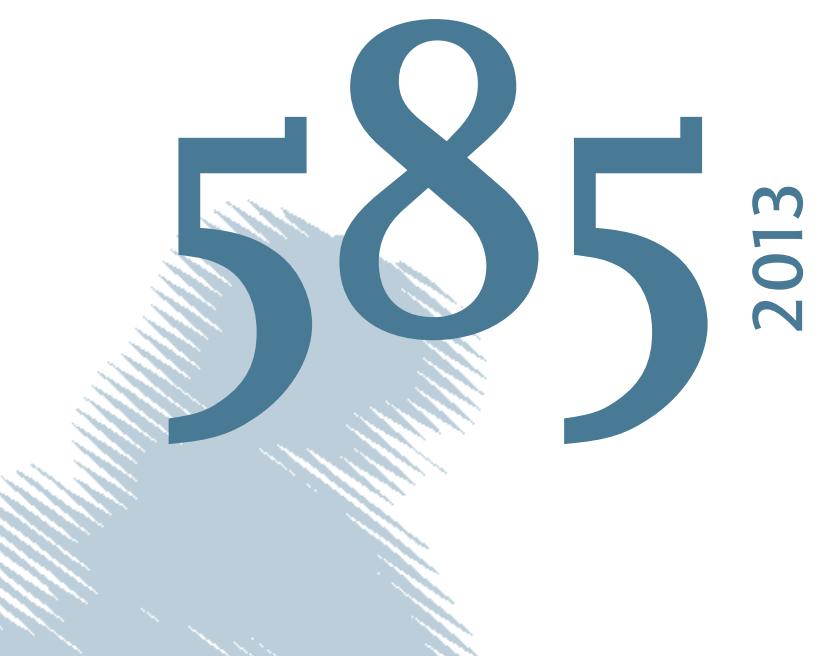

\section{Personality Changes in Couples - Partnership longevity and personality congruence in couples}




\section{SOEPpapers on Multidisciplinary Panel Data Research}

at DIW Berlin

This series presents research findings based either directly on data from the German SocioEconomic Panel Study (SOEP) or using SOEP data as part of an internationally comparable data set (e.g. CNEF, ECHP, LIS, LWS, CHER/PACO). SOEP is a truly multidisciplinary household panel study covering a wide range of social and behavioral sciences: economics, sociology, psychology, survey methodology, econometrics and applied statistics, educational science, political science, public health, behavioral genetics, demography, geography, and sport science.

The decision to publish a submission in SOEPpapers is made by a board of editors chosen by the DIW Berlin to represent the wide range of disciplines covered by SOEP. There is no external referee process and papers are either accepted or rejected without revision. Papers appear in this series as works in progress and may also appear elsewhere. They often represent preliminary studies and are circulated to encourage discussion. Citation of such a paper should account for its provisional character. A revised version may be requested from the author directly.

Any opinions expressed in this series are those of the author(s) and not those of DIW Berlin. Research disseminated by DIW Berlin may include views on public policy issues, but the institute itself takes no institutional policy positions.

The SOEPpapers are available at

http://www.diw.de/soeppapers

\section{Editors:}

Jürgen Schupp (Sociology)

Gert G. Wagner (Social Sciences, Vice Dean DIW Graduate Center)

Conchita D'Ambrosio (Public Economics)

Denis Gerstorf (Psychology, DIW Research Director)

Elke Holst (Gender Studies, DIW Research Director)

Frauke Kreuter (Survey Methodology, DIW Research Professor)

Martin Kroh (Political Science and Survey Methodology)

Frieder R. Lang (Psychology, DIW Research Professor)

Henning Lohmann (Sociology, DIW Research Professor)

Jörg-Peter Schräpler (Survey Methodology, DIW Research Professor)

Thomas Siedler (Empirical Economics)

C. Katharina Spieß (Empirical Economics and Educational Science)

ISSN: 1864-6689 (online)

German Socio-Economic Panel Study (SOEP)

DIW Berlin

Mohrenstrasse 58

10117 Berlin, Germany

Contact: Uta Rahmann | soeppapers@diw.de 
NOTICE: This is the author's version of a work that was accepted for publication in "Personality and Individual Differences". Changes resulting from the publishing process, such as peer review, editing, corrections, structural formatting, and other quality control mechanisms may not be reflected in this document. Changes may have been made to this work since it was submitted for publication. A definitive version was subsequently published in Personality and Individual Differences 54(2013), 7, pp. 832-835 and is online available at http://dx.doi.org/10.1016/i.paid.2012.12.007

\title{
Personality Changes in Couples
}

\section{Partnership Longevity and Personality Congruence in Couples}

\author{
Beatrice Rammstedt $^{1} \quad$ Frank M. Spinath ${ }^{3} \quad$ David Richter $^{2} \quad$ Jürgen Schupp $^{2}$ \\ ${ }^{1}$ GESIS Leibniz Institute for the Social Sciences, Mannheim \\ ${ }^{2}$ Socio-Economic Panel Study (SOEP) at the German Institute for Economic Research, \\ Berlin \\ ${ }^{3}$ University of Saarbrücken, Saarbrücken
}

Keywords: assortative mating, Big Five, personality, congruence, personality change, partnership

Correspondence concerning this manuscript should be addressed to Beatrice Rammstedt, GESIS Leibniz Institute for the Social Sciences, PO-Box 1221 55, D-68072 Mannheim, Germany. Email: beatrice.rammstedt@gesis.org. 


\begin{abstract}
Evidence of assortative mating according to personality was reported in a previous SOEP-based study (Rammstedt \& Schupp, 2008). Based on population representative data of almost 7,000 couples, high levels of congruence between spouses were found, which increased with marriage duration. Almost 5,000 of these couples were tracked over a five-year period with personality assessed at the beginning and end of this time, which allowed us to investigate the relationship between personality congruence and marriage duration longitudinally. Using this data, we investigated (a) whether personality congruence is predictive for partnership longevity and whether congruence therefore differs between subsequently stable and instable couples, (b) if stable couples become more congruent, and (c) if separated couples become less congruent with regard to their personality over time. The results provide initial evidence of personality congruence as a predictor for partnership longevity: the more congruent couples are in the personality domain of Openness, the more stable their partnership. In addition, we found no indications of an increase in personality congruence over time within the stable couples; within the separated couples, however, a strong decrease in congruence was detectable.
\end{abstract}

Word count: 183 
Birds of a feather flock together - this folk saying also seems to hold for personality. Assortative mating for personality was demonstrated in a previous study (Rammstedt \& Schupp, 2008) based on population-representative data of almost 7,000 couples, as well as in several other studies based on somewhat smaller and/or more selective samples (e.g., BleskeRechek, Remiker, \& Baker, 2009; Gonzaga, Carter, \& Buckwalter, 2010; McCrae, Martin, Hrebícková, Urbánek, Willemsen, \& Costa, 2008). However, assortative mating is not found to the same degree for all personality dimensions. In the aforementioned study by Rammstedt and Schupp, assortment was reported primarily for the Big Five domains Agreeableness, Conscientiousness, and Openness to Experiences, while for the remaining two domains Extraversion and Neuroticism, congruences were more or less non-existent.

In addition, Rammstedt and Schupp found that for the three domains Agreeableness, Conscientiousness, and Openness, congruence increased with marriage duration. There are two possible interpretations for this increase. On the one hand, it could be assumed that personality congruence is a major factor in the quality of a marriage. Lack of congruence might lead to increased friction and therefore end in separation or divorce. The finding that congruence is higher in long-term partnerships might therefore be moderated by the fact that incongruent partnerships ended earlier, resulting in a lower proportion of incongruent partnerships among the long-term couples in the sample. Consequently, we hypothesize personality congruence to be predictive for partnership longevity and assume congruence to be higher in couples who turn out to be stable than in couples separating in the years thereafter (Hypothesis 1). On the other hand, it could be argued that long-term couples become more similar in their personalities over time. For example, for someone less open to experience than his or her partner, joining this partner in cultural activities might make him or 
her more interested and thus more open. We could therefore assume a personality change towards higher congruence over time in stable couples (Hypothesis 2).

However, neither of the two alternative hypotheses is supported by data from previous studies. Gonzaga et al. (2010), using data from an online relationship service, and Caspi, Herbener, and Ozer (1992), using data from the 20-year Kelly Longitudinal Study of couples, found no evidence that couples' resemblance increased over time. In their study based on 51 student couples, Bleske-Rechek et al. (2009) found that intact couples did not differ less in their major personality dimensions than separated couples, thus contradicting our first assumption. As this study is based on a comparatively small and highly selective sample of young adults for whom partnerships and their duration presumably play a different role in their lives than for older respondents, this finding requires further investigation based on a less selective sample.

In addition to these two hypotheses, it might also be assumed that personality changes in couples who split up. A recent longitudinal study (Specht, Egloff, \& Schmukle, 2011) showed that separation from a partner and divorce have different impacts on personality. Individuals who separated from their partner became more agreeable; divorced individuals became more conscientious and men became more open after separation from their female partners. Specht et al. (2011), however, investigated these effects only on the individual level, not on the level of couples. If, however, both ex-partners become more agreeable and/or more conscientious to a similar extent, this would not affect the congruence between their personalities. Thus, the study by Specht et al. can be regarded as providing initial evidence of personality change after separation and/or divorce. Whether this change also affects the personality congruence of the (ex-)couples has not been investigated to our knowledge. The supportive results for personality change after major life events, however, let us assume that personality congruence of couples should decrease after separation (Hypothesis 3) 
In sum, the present study aims to investigate (a) whether personality congruence is predictive for partnership longevity and whether congruence therefore differs between couples who turn out to be stable versus instable. In addition, we aim to test (b) whether stable couples become more congruent over time, and (c) whether separated couples become less congruent over time. To test these questions, we analyzed data of 4,809 couples who were surveyed over a period of five years.

\section{Method}

\section{$\underline{\text { Participants }}$}

Analyses are based on data from the German Socio-Economic Panel Study (SOEP). The SOEP is a nationally representative longitudinal annual panel study of private households and individuals. In total, the SOEP data currently span 27 years, 1984 to 2010, with a participant base of roughly 22,000 persons, including residents of former West and East Germany, immigrants, and resident foreigners (Wagner, Frick, \& Schupp, 2007). For the present study, data from the survey years 2005 to 2010 were analyzed. Household members were only included if they lived with their heterosexual partner in 2005 and data on the partner were also available for each wave. The present sample consisted of 4,809 couples. The age of the male respondents (as assessed in 2005) varied between 19 and 95 years with a mean of $\mathrm{M}=52(\mathrm{SD}=14)$ years. The age of the female respondents ranged from 18 to 89 years with a mean of $\mathrm{M}=41(\mathrm{SD}=11)$ years. A total of 4,308 couples were married to each other. Of the 4,809 couples, 4,610 remained stable until 2010 and 199 separated within the six years of the survey period. Socio-demographic characteristics of these two subsamples are given in Table 1.

\section{$\underline{\text { Measures }}$}

Big Five. The Big Five personality dimensions were measured twice in the SOEP, first in 2005 and then again in 2009, using a short-scale measure of the Big Five Inventory (BFI; 
John, Donahue, \& Kentle, 1991; German Adaptation Lang, Lüdtke, \& Asendorpf, 2001; Rammstedt, 1997). Each Big Five domain is assessed by three items which were to be answered on a seven-point scale ranging from "does not apply" to "does apply." Factor analyses clearly replicated the Big Five factors (Dehne \& Schupp, 2007; Lang et al., 2011). Scale scores were computed on the basis of the highest loadings of the items and their classification according to the Big Five. Coefficient Alpha values (averaged across both administrations) of the resulting Big Five scales Extraversion, Agreeableness, Conscientiousness, Emotional Stability, and Openness were $.65, .50, .61, .61$, and .62. As the three items per dimensions were selected to cover a maximum bandwidth of each underlying dimension and thus with regard to their heterogeneity and not to their homogeneity, Coefficients Alpha - representing the item homogeneity - of the found magnitude were expectable. Retest stability for the five scales across a 6-week interval indicate sufficient stability with all coefficients exceeding .75 (Lang, 2005).

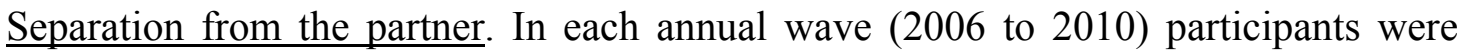
asked to indicate whether they separated from their partner within the last year. On the basis of these self-reports by both partners, a couple were regarded as "separated" if both spouses independently reported a separation in any of the years 2006 to 2010.

\section{Results}

A previous SOEP-based study (Rammstedt \& Schupp, 2008) had demonstrated personality congruence between spouses. In order to investigate to what extent a subsequent separation is associated with a lack of congruence in personality (Hypothesis 1), we compared levels of congruence for the Big Five dimensions in 2005 separately for couples who remained stable and for those who separated afterwards. ${ }^{1}$ As our two subsamples varied with regard to several socio-demographic characteristics, partial convergent correlations between males' and females' personalities were controlled for using both respondents' ages, their 
educational levels, their socio-economic status, and the duration of their marriage. As can be seen from Table 2, stable and instable couples showed a rather similar and substantial level of personality congruence in 2005 overall. Across all five domains, congruence was .21 for both the subsequently stable couples and those separating in the following years.

In the previous study, we found that personality congruence was greater for the dimensions Agreeableness, Conscientiousness, and Openness. This effect was confirmed here. However, the effect was more pronounced for the subsequently stable couples (mean congruence across these three dimensions .28 compared to .11 across Extraversion and Neuroticism). For couples who separated in the years thereafter we found less congruence for the three dimensions demonstrating assortative mating, while for the two domains identified as non-indicative, congruence was somewhat higher compared to the stable couples $(.19$ compared to .17). Congruence in Openness in particular varied between couples whose partnerships remained stable and those who split up in the next few years. While in the stable couples the congruence for Openness was .29 and thus comparable in size to the coefficients found for the total sample (cf. Rammstedt \& Schupp, 2008), congruence in Openness was markedly lower in the couples who later separated $(\mathrm{r}=.11, \mathrm{p}<.05)$. These results at least partially support or hypothesis that personality congruence is higher in couples who turn out to be stable than in couples subsequently separating. Even though this does not seem to be true for all five personality domains, we provide evidence for this hypothesized effect for the domain of Openness.

In a second step, we aimed to investigate to what extent couples became more similar in their personalities over the course of their relationship (Hypothesis 2). Therefore, we compared levels of congruence in the Big Five domains in 2005 with those assessed four years later within the subsample of the stable couples (see Table 2). The results clearly showed that no change in personality congruence was detectable for the stable couples. For 
the five domains, differences varied between -.01 and .01 with an overall mean of .00 . None of the differences reached significance.

Finally, we hypothesized that couples who separated within the five years after our initial assessment might have experienced greater changes in their personalities so that congruence between the partners decreased (Hypothesis 3). Results for the subgroup of separated couples (presented in the right-hand columns of Table 2) clearly supported this assumption. We found changes in the hypothesized direction for all five domains with an overall decrease in personality congruence of .15. This decrease, however, was strongest and only reached significance for the Openness dimension $(\Delta=.24, \mathrm{p}<.05)$.

\section{Discussion}

The present study aimed to investigate to what extent personality congruence is predictive of partnership longevity and in how far this congruence changes depending on partnership stability. An earlier study conducted in this field found no evidence of the predictability of personality congruence for partnership stability and separation (cf. BleskeRechek et al., 2009). As this study was based on a rather small and highly selective sample, however, the generalizability of these findings was questioned. The results of the present study indicated that personality congruence predicted the longevity of partnerships as postulated in our Hypothesis 1. This appeared to be the case in particular for the personality domain Openness, which was already identified in an earlier study as one of the major domains of personality in which couples showed congruence. Congruence in this domain was markedly lower in the later on separated couples than in the couples who remained stable. After separation, the congruence in Openness further decreased.

We found no evidence of the assumed increase in personality congruence within stable partnerships (Hypothesis 2). The congruence coefficients for stable couples at both 
assessment times were surprisingly similar. This finding is in line with earlier studies also reporting no changes in personality congruence in couples over time (Caspi et al., 1992; Gonzaga et al., 2010).

For those couples separated within the five years investigated, we did, however, identify strong changes in their personality congruence as postulated in Hypothesis 3. In 2005, i.e., at a time when the partnerships were still intact, personality congruence for the couples who later separated was - with the exception of Openness - more or less comparable to the congruence found for the subsequently stable couples. After separation, however, the personality congruence between the ex-spouses decreased to a near-to-zero level. The tendency for this decrease was found for all five domains, thus suggesting that couples became more different in their personalities in general after separation. The most pronounced decrease, however, was again found for Openness. Since the time interval between the two assessments was only four years, this degree of change in personality congruence was impressive. Thus, it seems that separation does not only affect the personality of individuals as shown by Specht et al. (2011) but affects both (ex-)spouses in such a way that their personality congruence is markedly decreased.

We would have liked to investigate to what extent these changes occur in the course of separation or only after separation (and therefore by the time that couples stopped living together). For these kinds of subgroup analyses, however, the present sample is still too small.

In sum, the results of our study provide some evidence of personality congruence being associated with partnership longevity: the more congruent couples are in the personality domain Openness, the more stable their relationship. In addition, we found no indications of an increase in personality congruence over time within the stable couples; within the separated couples, however, a strong decrease in congruence was detectable. 


\section{References}

Bleske-Rechek, A., Remiker, M. W., \& Baker, J. P. (2009). Similar From the Start: Assortment in Young Adult Dating Couples and Its Link to Relationship Stability Over Time. Individual Differences Research, 7, 142-158.

Caspi, A., Herbener, E. S., \& Ozer, D. J. (1992). Shared experiences and the similarity of personalities: A longitudinal study of married couples. Journal of Personality and Social Psychology, 62, 281-291.

Dehne, M., \& Schupp, J. (2007). Persönlichkeitsmerkmale im Soziooekonomischen Panel (SOEP) - Konzept, Umsetzung und empirische Eigenschaften. [Personality characteristics in the Socio-economic Panel Study (SOEP) - concept, implementation, and psychometric properties.] DIW Research Notes 2007-26. Berlin: DIW Berlin.

Ganzeboom, H. B.G., De Graaf, P., Treiman, D. J. (with De Leeuw, J.) (1992). A Standard International Socio-Economic Index of Occupational Status. Social Science Research, 1-56.

Gonzaga, G.C., Carter, S., \& Buckwalter, J.G. (2010). Assortative mating, convergence, and satisfaction in married couples. Personal Relationships, 17, 634-644.

John, O. P., Donahue, E. M., \& Kentle, R. L. (1991). The Big Five Inventory-Versions 4a and 54. Berkeley, CA: University of California,Berkeley, Institute of Personality and Social Research.

Lang, F. R. (2005). Erfassung des kognitiven Leistungspotenzials und der "Big Five" mit Computer-Assisted-Personal-Interviewing (CAPI): Zur Reliabilität und Validität zweier ultrakurzer Tests und des BFI-S. [Assessment of cognitive capabilities and the Big Five with 
Computer-Assisted Personal Interviewing (CAPI): Reliability and validity]. German Institute of Economic Research (Research Notes 9/2005), Berlin: DIW.

Lang, F. R., Lüdtke, O., \& Asendorpf, J. (2001). Testgüte und psychometrische Äquivalenz der deutschen Version des Big Five Inventory (BFI) bei jungen, mittelalten und alten Erwachsenen. [Validity and psychometric equivalence of the German version of the Big Five Inventory in young, middle-aged and old adults.] Diagnostica, 47, 111-112.

Lang, F.R., John, D., Lüdtke, O., Schupp, J., \& Wagner, G.G. (2011). Short Assessment of the Big Five: Robust Across Survey Methods Except Telephone Interviewing. Behavior Research Methods, 43, 548-567.

McCrae, R. R., Martin, T. A., Hrebícková, M., Urbánek, T., Willemsen, G., \& Costa, P. T., Jr. (2008). Personality Trait Similarity Between Spouses in Four Cultures. Journal of Personality, 76, 1137-1163.

Rammstedt, B. (1997). Die deutsche Version des Big Five Inventories (BFI): Übersetzung und Validierung eines Fragebogens zur Erfassung des Fünf-Faktoren-Modells der Persönlichkeit [The German Version of the Big Five Inventory (BFI): Translation and Validation of a Questionnaire for the Measurement of the Five Factor Model of Personality]. Unpublished thesis, University of Bielefeld, Bielefeld, Germany.

Rammstedt, B., \& Schupp, J. (2008). Only the congruent survive - personality similarities in couples. Personality and Individual Differences, 45, 533-535.

Specht, J., Egloff, B., \& Schmukle, S. C. (2011). Stability and change of personality across the life course: The impact of age and major life events on mean-level and rank-order stability of the Big Five. Journal of Personality and Social Psychology, 101, 862-882. 
Wagner, G.G., Frick, J.R., \& Schupp, J. (2007). The German Socio-Economic Panel Study (SOEP) - Scope, Evolution and Enhancement. Schmollers Jahrbuch, Journal of Applied Social Studies, 127, 139-169. 


\section{$\underline{\text { Footnotes }}$}

${ }^{1}$ In the full sample stereotype congruence between males and females is .00 for each Big Five dimension. Controlling for stereotype congruence would therefore not affect the congruence between the spouses. 
Table 1.

Sociodemographic characteristics (in 2005) of the stable and separated couples

\begin{tabular}{|c|c|c|c|c|}
\hline & \multicolumn{2}{|c|}{$\begin{array}{l}\text { Stable couples } \\
\qquad(\mathrm{N}=4,610)\end{array}$} & \multicolumn{2}{|c|}{$\begin{array}{l}\text { Separated couples } \\
\qquad(\mathrm{N}=199)\end{array}$} \\
\hline & M & SD & M & SD \\
\hline Age (male spouse) & 51.9 & 13.7 & 44.4 & 14.2 \\
\hline Age (female spouse) & 49.2 & 13.6 & 39.3 & 13.4 \\
\hline No. of children (male spouse) & .62 & .95 & .68 & .95 \\
\hline No. of children (female spouse) & .62 & .95 & .81 & 1.02 \\
\hline ISCED-1997 (male spouse) & 3.9 & 1.6 & 3.8 & 1.6 \\
\hline ISCED-1997 (female spouse) & 3.6 & 1.5 & 3.5 & 1.5 \\
\hline ISEI (male spouse) & 30.5 & 28.1 & 34.3 & 24.8 \\
\hline ISEI (female spouse) & 23.2 & 26.7 & 27.7 & 26.9 \\
\hline No. of children (male spouse) & .65 & .97 & .68 & .95 \\
\hline No. of children (female spouse) & .66 & .97 & .81 & 1.02 \\
\hline Marriage duration & 24.2 & 14.6 & 14.0 & 10.0 \\
\hline
\end{tabular}

Note. ISCED = International Classification of Educational Degrees. ISEI = International Socio-Economic Index of Occupational Status (ranging between $16=$ low and 90= high; Ganzeboom, De Graaf, \& Treiman, 1992); source: SOEP V27. 
Table 2.

Personality congruence in 2005 and 2009 separately for stable and separated couples.

\begin{tabular}{|c|c|c|c|c|c|c|c|c|}
\hline & \multicolumn{3}{|c|}{2005} & \multicolumn{3}{|c|}{2009} & \multicolumn{2}{|c|}{ Diff over Time } \\
\hline & Stable & Separated & Diff & Stable & Separated & Diff & Stable & Separated \\
\hline Extraversion & .07 & .07 & .00 & .06 & -.07 & .13 & .01 & .14 \\
\hline Agreeableness & .25 & .25 & .00 & .26 & .11 & $.15^{*}$ & -.01 & .14 \\
\hline Conscientiousness & .31 & .22 & .09 & .30 & .12 & $.18 * *$ & .01 & .10 \\
\hline Neuroticism & .14 & .26 & -.12 & .15 & .13 & .02 & -.01 & .13 \\
\hline Openness & .29 & .11 & $.18^{*}$ & .28 & -.13 & $.41 * * *$ & .01 & $.24^{*}$ \\
\hline Overall Mean & .21 & .18 & .03 & .21 & .03 & .18 & .00 & .15 \\
\hline Mean $(\mathrm{A}, \mathrm{C}, \mathrm{O})$ & .28 & .19 & .09 & .28 & .03 & $.25 * * *$ & .00 & .16 \\
\hline Mean $(E, N)$ & .11 & .17 & -.06 & .11 & .03 & .08 & .00 & .14 \\
\hline
\end{tabular}

Note. ${ }^{*} \mathrm{p}<.05,{ }^{* *} \mathrm{p}<.01,{ }^{* * *} \mathrm{p}<.001$; correlations controlled for the spouse's age, level of education, and socio-economic status as well as marriage duration; source: SOEP V27. 